\title{
Multiple Output Battery Charging Circuit for Bikers
}

\author{
Ali Sinan CABUK
}

\begin{abstract}
Bikers want to charge their devices containing batteries (such as smart phones, bicycle headlight, head cameras), which they need in their daily lives, with the energy produced by their bicycles. A device capable of storing kinetic energy of bikers contributes to environment friendly electric power generation. This paper presents a multiple output battery charging circuit design for bikers. Proposed design consists of a dynamo capable of producing $12 \mathrm{~V}$ and it charges $2 \times 4000 \mathrm{mAh}$ storage batteries with a buck converter that produces an output voltage of $1.29 \mathrm{~A} 4.2 \mathrm{~V}$. Li-ion batteries are the most suitable batteries for portable storage applications due to their compact size, light weight and long-life time features. $2 \times 4000 \mathrm{mAh}$ Li-ion batteries charge a $5 \mathrm{~V} 2000 \mathrm{mAh}$ battery with a boost converter. Proposed method is simulated using MATLAB/Simulink. The simulation results are compared with the experimental results. The simulation and experimental results are in accordance with each other. A biker using the device suggested in the study will be able to ride an average of 2 hours a day and store the energy to fully charge the smart phone or bike headlight or head camera with 1 week of use.
\end{abstract}

Keywords: bike; boost converter; buck converter; charger; sustainable; transportation

\section{INTRODUCTION}

The use of bicycles as a transportation vehicle is increasing day by day. Among the reasons for that are the increase in traffic problems in cities and air pollution as a result of carbon gas emission caused by the vehicles $[1,2]$. At this point, bicycles can be preferred as a transportation vehicle since they can run without any fuel, and they are not affected by traffic [3]. Many cities in the world encourage the use of bicycles by increasing the number of bicycle paths separated from vehicle traffic [4]. In metropolises, the importance of sustainable transportation concept is supported by municipality. A proper cycling network and proper riding infrastructure encourage cycling, increasing physical activity, reducing the intensity of travel by vehicle and reducing negative effects on the environment [5-7]. With the increasing rate of bicycle use, the idea of using the energy obtained from the movement of the bicycle for battery charging has emerged.

DC-DC converters are used to obtain required voltage values of devices with low or high DC voltage levels. The most commonly used converters are buck and boost converters among others. One of the most preferred fields of study for these converters is solar panel applications. In such applications, researchers use capacitors as direct voltage busbars [8]. SEPIC converter topologies are another preferred method for similar storage applications. SEPIC converters are used for both step up and step down voltage. Especially a lithium-ion battery with very high accuracy and stability is used in applications [9]. The boost DC/DC converters for lithium polymer batteries with low input-output voltage values such as $6-10 \mathrm{~V}$ give better results in applications. In addition, the output capacitor in the amplifying DC / DC converter circuit ensures that the output voltage ripple is lower [10]. A Hybrid Boost DCDC converter can be used for energy harvesting and energy storage applications. A Hybrid Boost DC-DC convertor with ZVS switching approach has rated losses and high efficiency and is obtained by introducing soft switching techniques into the conventional converters. It is known that switching losses and low conduction occur with soft switching approach. This type of switching method is suitable for the goals of reaching higher overall efficiency such as $87 \%$ - 98\%. Hybrid Boost DC-DC converter recommended for this combines pulse width modulated and resonant configuration [11]. The use of Cuk converters for electricity generation from bicycle kinetic energy has been found to be suitable for e-bikes. A Cuk converter method is suitable for these types of bicycles with high current requirements. This method is expensive in low current applications [12]. Constant current or constant voltage must be used to charge Li-ion batteries [13, 14]. It is common to use buck converters that have a lightweight charger and are high-efficient for electric bikes [15]. Compared to other batteries, the Li-ion batteries are largely used in many applications due to their superior power density, high efficiency, low self-discharge and more life cycle. Li-ion battery is the most preferred among rechargeable batteries. Optimization of charge on Li-ion battery operated bike is one of the most important subjects of the charging batteries $[16,17]$.

In this study, low cost electric energy recovery system has been established. The proposed system developed for cyclists is thought to contribute to the concept of environment friendly and sustainable cities. Energy storage is provided independent of the network voltage with the proposed circuit. It is predicted that it will lead to a slight decrease in annual energy expenditure with the increase in the use of this system.

In this paper, the system necessary for converting motion energy to electrical energy was designed and modelled. This system consists of a dynamo as a rotating electric machine, three DC/DC converters and a battery. The system was designed to provide different levels of output voltage so that the obtained electrical energy can be used in different devices. The supply voltage of the proposed system is dynamo with $12 \mathrm{~V}$ output. The storage battery targeted for charging is a Li-ion type $2 \times 4000 \mathrm{mAh}$ battery. These batteries will charge the smartphone and bicycle headlight for cyclists. In addition, the device in the article can be connected to other battery systems that are suitable for charging with $5 \mathrm{~V}, 2 \mathrm{~A}$ or $8.4 \mathrm{~V}, 1.8 \mathrm{~A}$. 


\section{THEORY OF DC/DC CONVERTER}

Many regulated power electronics applications utilize the DC/DC converters. In order to transform the unregulated DC input into a controlled DC output at a desirable voltage, switch-mode DC/DC converters are employed. These converters are buck, boost, buck-boost, Cuk, full bridge, push-pull, forward, flyback and SEPIC $[18,19]$. The maximum voltage value of the dynamo used in this article study is $12 \mathrm{~V}$ and the batteries in the charging unit have a value of $5 \mathrm{~V}$. In road tests with a bicycle, it was observed that the voltage produced by the dynamo was in the range of $5-6 \mathrm{~V}$ when driving with the lowest speed. Therefore, a buck converter was preferred.

In buck DC/DC converter circuits, the input voltage is higher than the output voltage. The operating principle of the buck DC/DC converter circuit is related to the amount of energy stored in the inductance [19, 20]. The buck $\mathrm{DC} / \mathrm{DC}$ converter circuit diagram is as in Fig. 1.

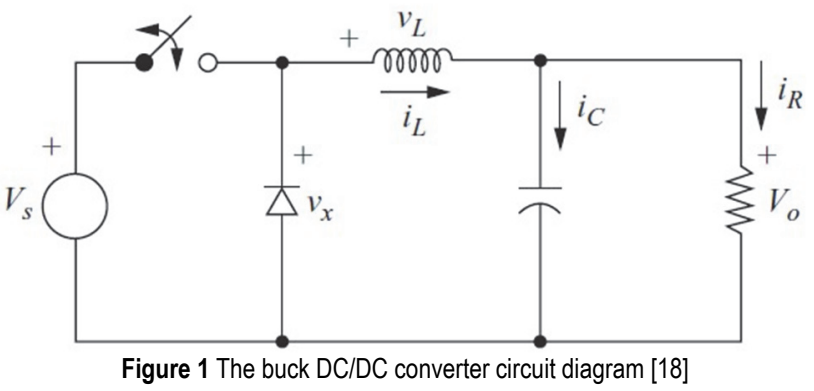

When the switch is closed in Fig. 1, the diode in the circuit is reverse-biased. The voltage across the inductor is

$v_{L}=V_{s}-V_{0}=L \frac{\mathrm{d} i_{L}}{\mathrm{~d} t}$

where $V_{S}$ is supply voltage, $V_{0}$ is voltage drop of load and $L$ is inductance [18]. Since the change of current with respect to time in this circuit is linear:

$$
\frac{\mathrm{d} i_{L}}{\mathrm{~d} t}=\frac{\Delta i_{L}}{\Delta t}
$$

While analysing the circuit, the period of switching is $T$; the switch is closed for time $D T$ and open for time (1$D) T$. The derivative of the current being positive constant, the current increases linearly and the change in current while the switch is closed is calculated by modifying the Eq. (2) $[18,19]$. Then:

$$
\begin{aligned}
& \frac{\Delta i_{L}}{\Delta t}=\frac{V_{s}-V_{0}}{L} \\
& \left(\Delta i_{L}\right)_{\text {conduct }}=\left(\frac{V_{s}-V_{0}}{L}\right) D T
\end{aligned}
$$

In Eq. (4), the time change is expressed by $D T$, which is the conduction time of the switching element. While the switching element is in the cut, the energy stored in the inductance is carried to the load through the diode. Voltage drop of the inductance:

$v_{L}=-V_{0}=L \frac{\mathrm{d} i_{L}}{\mathrm{~d} t}$

Eq. (5) is also valid when 2 switching elements are in the cut. However, the change when the switching element is in the cut is expressed by $(1-D) T$. Then

$$
\left(\Delta i_{L}\right)_{c o t-o f f}=\left(\frac{-V_{0}}{L}\right)(1-D) T
$$

In the steady state, the total current change on the inductance during the conduction and cut-off times is zero. Hence:

$$
\begin{aligned}
& \left(\Delta i_{L}\right)_{\text {conduct }}+\left(\Delta i_{L}\right)_{\text {cot-off }}=0 \\
& \left(\frac{V_{s}-V_{0}}{L}\right) D T+\left(\frac{-V_{0}}{L}\right)(1-D) T=0 \\
& \left(\frac{V_{0}}{V_{s}}\right)=D
\end{aligned}
$$

where $D$ is the duty ratio of the square wave. Since $D<1$, it is observed that the input voltage is higher than the output voltage $\left(V_{0}<V_{s}\right)$.

The value of the capacitor element in the buck converter circuit is the factor that determines the output voltage ripple. The change of capacitor current according to time is given in Fig. 2 [18].

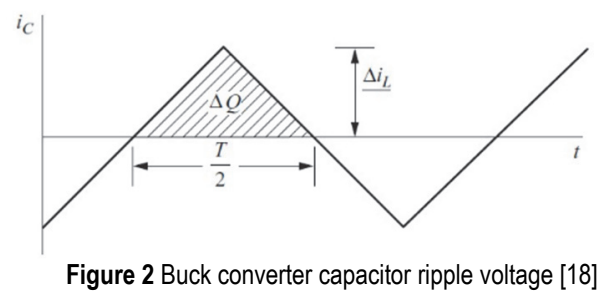

The $\Delta Q$ field seen in Fig. 2 represents the charge change of the capacitor. From the load change equation of the capacitor:

$\Delta Q=C \Delta V_{0}$

$\Delta Q=\frac{1}{2}\left(\frac{T}{2}\right)\left(\frac{\Delta i_{L}}{2}\right)$

$\Delta V_{0}=\frac{T \Delta i_{L}}{8 C}$

If the value of $\Delta i_{L}$ in Eq. (6) $[18,19]$ is replaced here:

$\frac{\Delta V_{0}}{V_{0}}=\frac{1-D}{8 L C f^{2}}$ 
$\frac{\Delta V_{0}}{V_{0}}$ is the ripple as a fraction of the output voltage.

The boost converters are the same as the buck converters in terms of the circuit elements used [18, 19, 21]. However, the arrangement of these elements in the circuit is different. A boost converter circuit diagram is given in Fig. 3 [18].

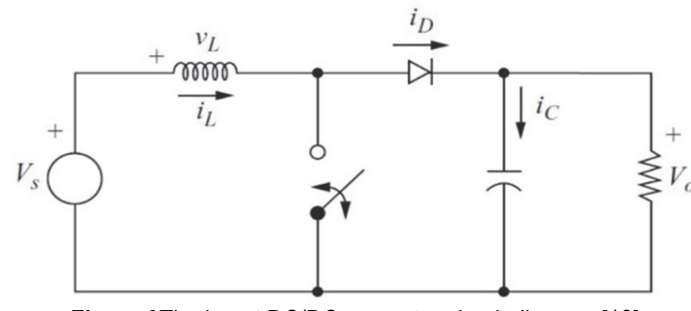

Figure 3The boost DC/DC converter circuit diagram [18]

Circuit analysis is performed by examining the change of inductance current for cases where the switching element is in conduct or in cut-off. When the switching element is in conduction:

$v_{L}=V_{s}=L \frac{\mathrm{d} i_{L}}{\mathrm{~d} t}$

$\frac{\mathrm{d} i_{L}}{\mathrm{~d} t}=\frac{\Delta i_{L}}{\Delta t}=\frac{V_{S}}{L}$

$\left(\Delta i_{L}\right)_{\text {conduct }}=\left(\frac{V_{s}}{L}\right) D T$

Meanwhile, the inductance voltage equals the source voltage and energy is kept in the inductance. When the switching element switches off, the inductance acts as a current source as a result of the energy kept in the inductance and transfers the stored energy to the load through the diode $[18,22]$. If circuit analysis is made for the situation where the switching element is cut-off:

$v_{L}=V_{s}-V_{0}=L \frac{\mathrm{d} i_{L}}{\mathrm{~d} t}$

$\frac{\mathrm{d} i_{L}}{\mathrm{~d} t}=\frac{\Delta i_{L}}{\Delta t}=\frac{V_{s}-V_{0}}{L}$

$\left(\Delta i_{L}\right)_{\text {cutoff }}=\left(\frac{V_{s}-V_{0}}{L}\right)(1-D) T$

In steady state Eq. (20) also applies to the boost converter. Therefore,

$\frac{V_{s}}{L} D T+\frac{V_{s}-V_{0}}{L}(1-D) T=0$

$\frac{V_{0}}{V_{s}}=\frac{1}{1-D}$
The input voltage is smaller than the output voltage $\left(V_{0}\right.$ $>V_{s}$ ) for $D<1$ in Eq. (21). The value of the capacitor element defines the output voltage ripple in the boost converter circuits $[18,19]$. The change of capacitor current according to time is given in Fig. 4.

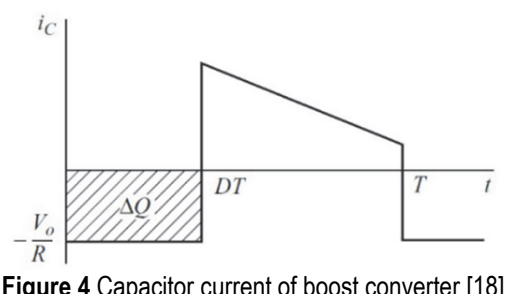

The $\Delta Q$ field seen in Fig. 4 expresses the charge change of the capacitor [18]. From the load change equation of the capacitor:

$\Delta Q=C \Delta V_{0}$

$\frac{V_{0}}{R} D T=C \Delta V_{0}$

$\frac{\Delta V_{0}}{V_{0}}=\frac{D}{R C f}$

\section{BATTERY MANAGEMENT 3.1 Battery Types}

There are many types of batteries with different chemical structures. These chemical differences cause batteries to differ from each other in many respects such as volume, weight, energy density, charge-discharge techniques. Batteries can basically be divided into two groups as primary type (non-rechargeable) and secondary type (rechargeable) batteries. Chemical reaction during discharge in primary type batteries is unidirectional. Therefore, it is not possible to recharge and reuse the battery. The chemical reaction in the secondary battery is bidirectional. Therefore, this type of batteries can be both discharged and rechargeable [23].

Batteries available in market conditions are Lithium Ion (Li-ion), Nickel Cadmium (NiCd), Nickel-Metal Hydride (NiMH), Sealed Lead Acid (SLA) and Reusable Alkaline.

Nickel Cadmium (NiCd) battery is low in energy density, high discharge rate. Nickel-Metal Hydride (NiMH) batteries have lower load current and poor cycle life. Sealed Lead Acid (SLA) batteries have high weight and are used in large power applications. Reusable Alkaline batteries have low power and limited cycle life. Lithium Ion (Li-ion) batteries have long life and high energy density.

According to Tab. 1, we can state that Li-ion batteries have advantage over other battery types.

The nominal cell voltage of the battery can get vary depending on the chemical content of the battery and is generally between $3.3 \mathrm{~V}$ and $4.0 \mathrm{~V} \mathrm{Li}$-ion batteries have a high cell voltage value. In addition, in Li-ion batteries, the memory effect seen in Nickel-based batteries is not observed. The battery memory effect is seen in nickel- 
based batteries, but there is no memory effect in Li-ion batteries. Today, Li-ion battery technology is the fastest growing battery technology [23-25].

Table 1 Properties of the most commonly used batteries [24]

\begin{tabular}{|c|c|c|c|c|c|}
\hline Parameters & $\mathrm{NiCd}$ & $\mathrm{NiMH}$ & SLA & Li-ion & $\begin{array}{l}\text { Reusable } \\
\text { Alkaline }\end{array}$ \\
\hline $\begin{array}{c}\text { Energy } \\
\text { density / } \\
\mathrm{Wh} / \mathrm{kg}\end{array}$ & $40-60$ & $60-80$ & 30 & 100 & 80 \\
\hline $\begin{array}{c}\text { Internal } \\
\text { Resistance / } \\
\mathrm{m} \Omega \\
\end{array}$ & $\begin{array}{l}100-300 \\
6 \mathrm{~V} \text { pack }\end{array}$ & $\begin{array}{c}200-800 \\
6 \text { Vpack }\end{array}$ & $\begin{array}{c}<100 \\
12 \text { Vpack }\end{array}$ & $\begin{array}{c}300- \\
5007.2 \\
\text { V pack }\end{array}$ & $\begin{array}{c}200- \\
20006 \mathrm{~V} \\
\text { pack }\end{array}$ \\
\hline Cycle life & 1500 & 500 & $200-300$ & $\begin{array}{l}500- \\
1000\end{array}$ & 10 \\
\hline $\begin{array}{c}\text { Fast charge } \\
\text { time / h }\end{array}$ & $1-1.5$ & $2-4$ & $8-16$ & $3-4$ & $2-3$ \\
\hline $\begin{array}{l}\text { Overcharge } \\
\text { tolerance }\end{array}$ & moderate & low & high & $\begin{array}{l}\text { very } \\
\text { low }\end{array}$ & moderate \\
\hline $\begin{array}{c}\text { Cell voltage } \\
\text { (Nominal) / } \\
\mathrm{V}\end{array}$ & 1.2 & 1.2 & 2 & 3.6 & 1.5 \\
\hline $\begin{array}{c}\text { Operating } \\
\text { temperature / } \\
\mathrm{C} \\
\end{array}$ & $\begin{array}{l}-40 \\
\text { to }+60\end{array}$ & $\begin{array}{l}-20 \text { to } \\
+60\end{array}$ & $\begin{array}{l}-20 \\
\text { to }+60\end{array}$ & $\begin{array}{l}-20 \\
\text { to }+60\end{array}$ & 0 to +65 \\
\hline $\begin{array}{c}\text { Maintenance } \\
\text { requirement }\end{array}$ & $\begin{array}{c}30-60 \\
\text { days }\end{array}$ & 60 days & $\begin{array}{c}\text { 3-6 } \\
\text { months }\end{array}$ & not req. & not req. \\
\hline
\end{tabular}

Li-ion batteries contain lithium metal oxide in the cathode and a carbon-based substance such as graphite in the anode. The discharging or charging of the battery takes place by the exchange of lithium ions between the electrodes. There are many different types of Li-ion batteries that have been produced to date. These Li-ion battery types are similar in structure. However, they differ from each other in terms of battery performance according to the material used in the cathode. An example of commonly used Li-ion battery types are Lithium Iron Phosphate, Lithium Cobalt Oxide, Lithium Titanite and Lithium Manganese Oxide [24].

When the characteristics of the battery and the demands of the bikers were examined, it was decided that the most suitable battery for the study within the scope of the article was Li-ion. In terms of compact size, light weight and long run time, 2 x $4000 \mathrm{mAh}$ capacity $5 \mathrm{~V}$ Liion batteries were used for the targeted charging devices.

\subsection{Battery Charging Managements}

Due to the bidirectional nature of the chemical reactions of secondary batteries, they can be recharged and reused. However, there are criteria to be considered when charging these batteries. Examples of these criteria are: the charging current is within the limits specified in the technical document of the battery, suitable ambient temperature, the depth of discharge (DoD) of the battery and the selection of charging method suitable for the chemical structure of the battery. Constant voltage, constant current, taper current, pulse current, and constant current-voltage charging methods are the available battery charging methods. The constant current-constant voltage charging method, which is the most suitable method for the structure in this study, was used [26, 27].

The charging process of the constant current-constant voltage is done in two steps. Primarily, the current of the battery keeps constant till the battery voltage becomes equal to the rated voltage. Then, the current of the battery drops gradually till it reaches the determined value. During this step, charging voltage holds constant. Since the current keeps stable at the first step of charge, the disadvantage of high starting current flow in constant voltage topology is eliminated. The second step is constant voltage topology. Thus, the overcharging problem with constant current method is also prevented. Because of these advantages, the constant current-constant voltage method is appropriate for high performance applications. The drawback of this method is that it is complex while charging of the battery, exceeding the maximum voltage can result in battery explosion and the risk of fire. The best solution to charge Li-ion batteries is constant current-constant voltage charging technique. In Fig. 5, the current-voltage profile curve of the constant current-constant voltage method is shown $[26,27]$.

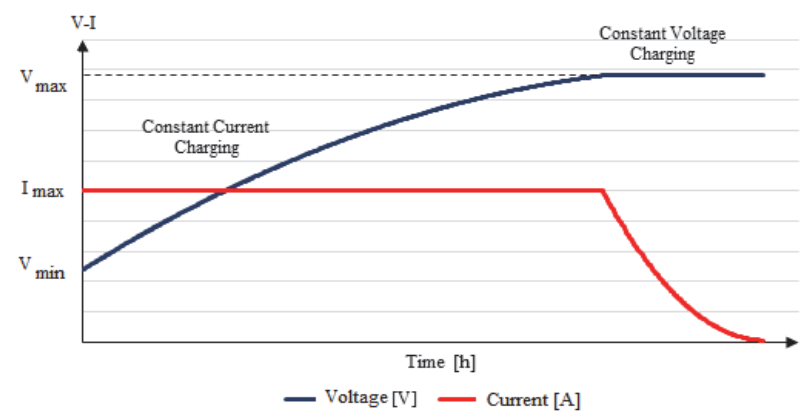

Figure 5 Current- voltage profiles curve[26, 27]

\section{DESIGN OF BATTERY CHARGING CIRCUIT}

Due to their clean and eco-friendly features, the use of bicycles as a transportation vehicle is increasing day by day. Bicycle use has a great impact on urban traffic, especially in big cities. This transportation vehicle, which has many superior features for the environment and human health, can also contribute to the electrical energy needs of the bikers. This electrical energy can be produced by the dynamo, which can be quite cheap and easily attached to bicycles. The bikers need to charge the batteries of a cell phone and bicycle lights.

The flowcharts of the multiple output battery charging system for bikers, which are the subject of this study, are as shown in Fig. 6.

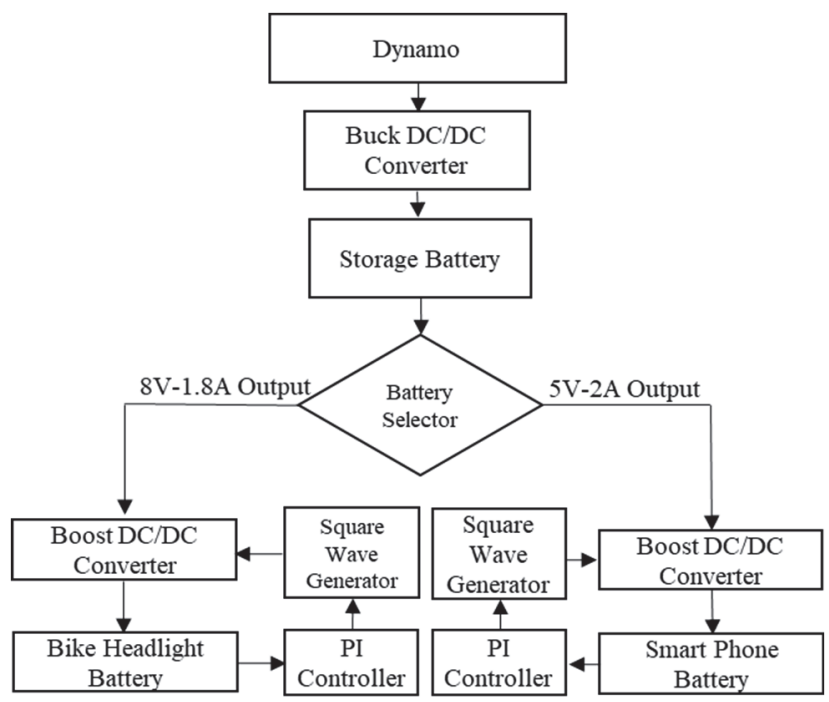

Figure 6 Battery charging system flowchart 
The designed system consists of a $12 \mathrm{~V}$ dynamo, two Li-ion batteries as $4000 \mathrm{mAh}$ connected in parallel as a storage battery, a smartphone and a bicycle light. A buck converter is designed to transfer energy from the dynamo to the storage battery with constant current-constant voltage charging method. DC/DC converter circuit modelling has been done to provide energy transfer from the storage battery to the smart phone and the bicycle light batteries with constant voltage method. The dynamo used in the charging system gives a maximum $12 \mathrm{~V}$ output. In this study, three different situations involving riding the bike at low, medium and high speeds were analysed. For these three cases, it is assumed that the dynamo produces respectively $5 \mathrm{~V}, 7 \mathrm{~V}$ and $12 \mathrm{~V}$. These values are determined by measuring the voltage in the dynamo's road tests.

The design of the charging circuit started with the buck converter model given in the MATLAB / Simulink circuit in Fig. 7.

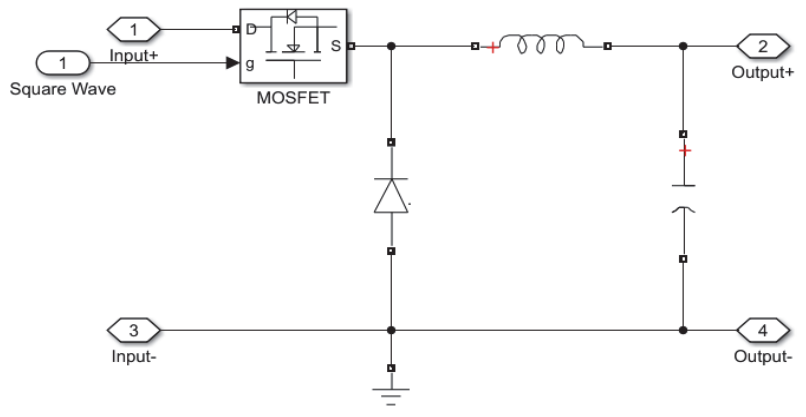

Figure 7 Design of buck DC-DC converter

Inductance and capacitor values, which are very important in terms of output voltage and current waveforms, are determined with Eq. (25) to Eq. (29) [18, 19].

$D_{\min }=\frac{V_{0_{\min }}}{V_{s}}$

$D_{\text {maks }}=\frac{V_{0_{\text {maks }}}}{V_{s}}$

$L_{\text {min }}=\frac{V_{s}-V_{0_{\min }}}{\Delta i_{L} \cdot I_{0} \cdot f} \cdot D_{\text {min }}$

$L_{\text {min }}=\frac{V_{s}-V_{0_{\text {maks }}}}{\Delta i_{L} \cdot I_{0} \cdot f} \cdot D_{\text {maks }}$

$C=\frac{1-D_{\min }}{8 \cdot L \cdot \frac{\Delta V_{0}}{V_{0}} \cdot f^{2}}$

Buck converter circuit parameters are determined as in Tab. 2.

After the design of the buck converter circuit, the design of the PI control circuit was done. The PI control circuit created with MATLAB / Simulink is as shown in Fig. 8.
Table 2 Buck converter circuit parameters

\begin{tabular}{|c|c|c|}
\hline Parameters & Minimum & Maximum \\
\hline Input Voltage / V & 0 & 12 \\
\hline Input Current / A & 0 & 0.5 \\
\hline Output Voltage / V & 3 & 4.2 \\
\hline Output Current / A & 0.03 & 1.29 \\
\hline Efficiency / \% & \multicolumn{2}{|c|}{90} \\
\hline Frequency / kHz & \multicolumn{2}{|c|}{20} \\
\hline Inductance Current Fluctuation $\left(\Delta \mathrm{i}_{\mathrm{L}}\right)$ & \multicolumn{2}{|c|}{0.01} \\
\hline Output Voltage Fluctuation $\left(\Delta V_{\mathrm{o}} / V_{\mathrm{o}}\right)$ & \multicolumn{2}{|c|}{0.45} \\
\hline$K_{p}$ & \multicolumn{2}{|c}{} \\
\hline$K_{i}$ & \multicolumn{2}{|c|}{} \\
\hline
\end{tabular}

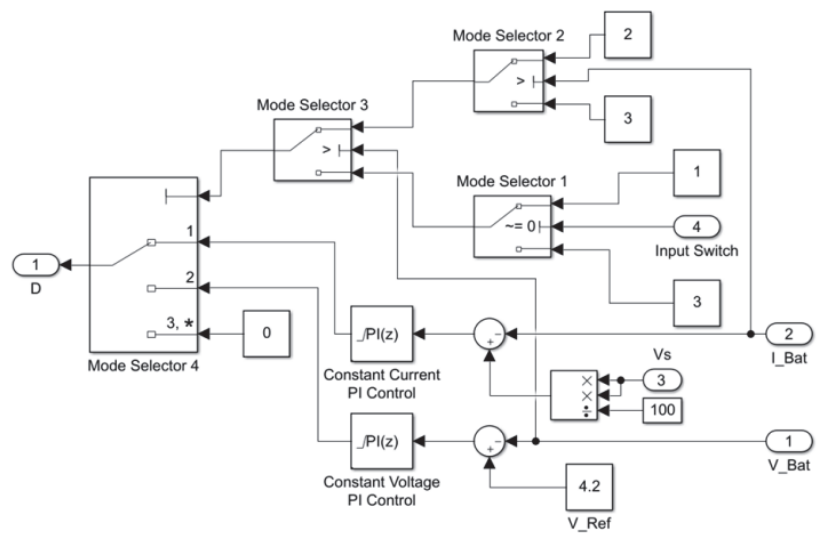

Figure 8 MATLAB/Simulink model of PI control circuit

Constant current-constant voltage charging method has been applied to transfer the electrical energy obtained from the dynamo as a result of the movement of the bicycle to the storage batteries more efficiently. Therefore, in addition to the PI control circuit, the charging mode selection algorithm has been developed with switches called mode selector switches in Fig. 4.

The charge mode selection algorithm flow chart created is given in Fig. 9.

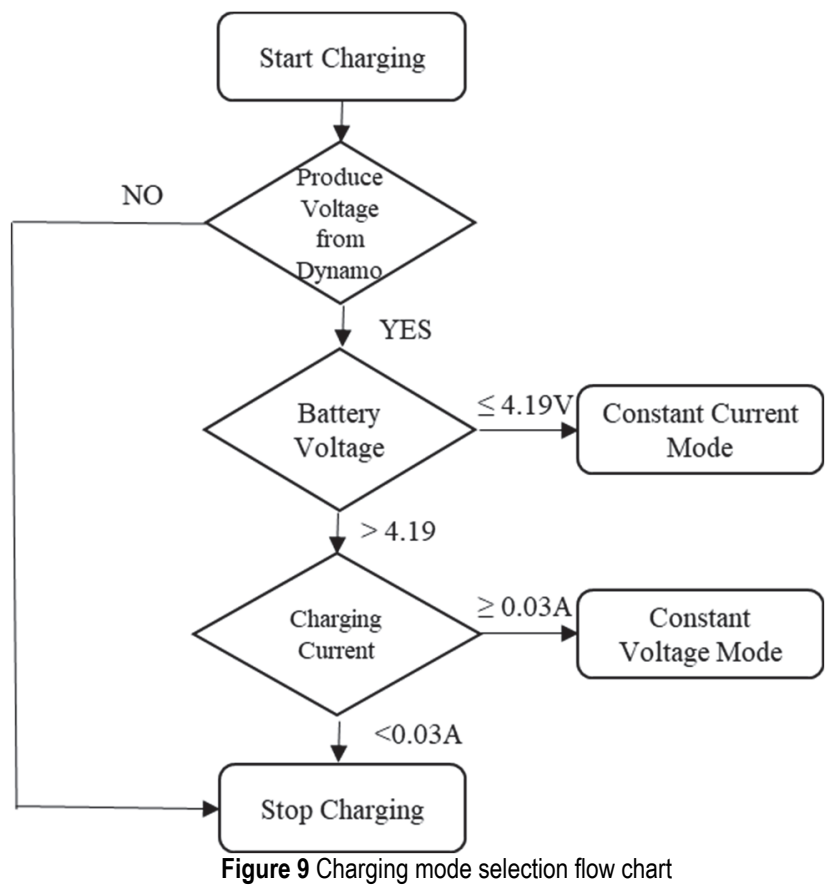


The buck DC-DC converter design in accordance with the flow chart is as in Fig. 10.

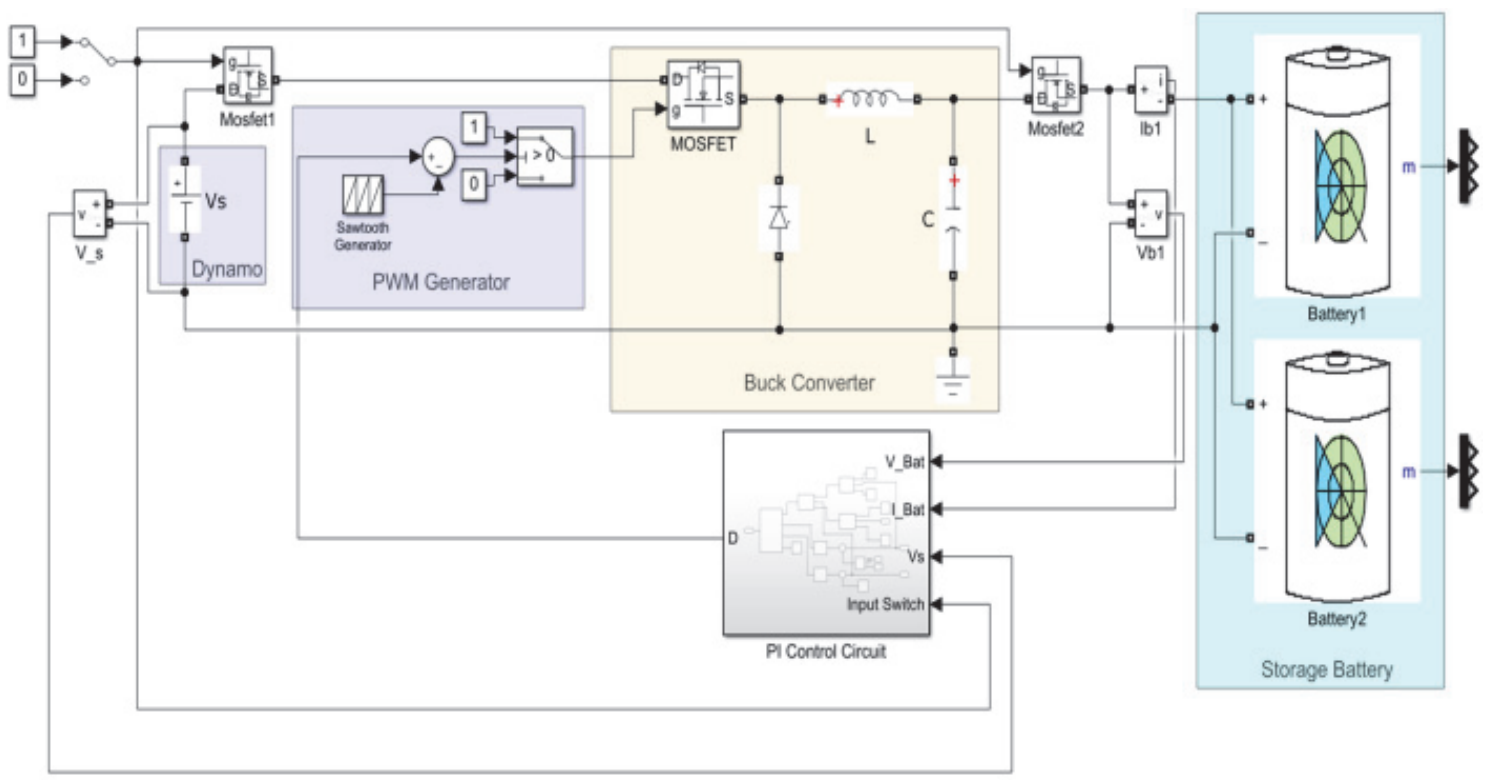

Figure 10 MATLAB/Simulink model of buck converter

The first part of this study is the circuit that will charge the battery with dynamo energy, and the second part is the circuit that will charge the user devices as cell phone and bike light with this battery. Circuit parameters for the boost converter design between the storage battery and the user device to be charged are as given in Tab. 3 .

\begin{tabular}{|c|c|c|}
\hline Parameters & Minimum & Maximum \\
\hline Input Voltage / V & 3 & 4.2 \\
\hline Input Current / A & 2.65 & 3.7 \\
\hline Output Voltage / V & 5 & \\
\hline Output Current / A & 2 & \\
\hline Efficiency / \% & \multicolumn{2}{|c|}{90} \\
\hline Frequency / kHz & \multicolumn{2}{|c|}{50} \\
\hline $\begin{array}{l}\text { Inductance Current Fluctuation } \\
\left(\Delta i_{L}\right) / \%\end{array}$ & \multicolumn{2}{|c|}{20} \\
\hline $\begin{array}{l}\text { Output Voltage Fluctuation } \\
\left(\Delta V_{\mathrm{o}} / V_{\mathrm{o}}\right)\end{array}$ & \multicolumn{2}{|c|}{0.01} \\
\hline$K_{p}$ & \multicolumn{2}{|c|}{0.15} \\
\hline$K_{i}$ & \multicolumn{2}{|c|}{4} \\
\hline
\end{tabular}

The design of the charging circuit modelled with the boost converter design given in the MATLAB / Simulink circuit in Fig. 11.

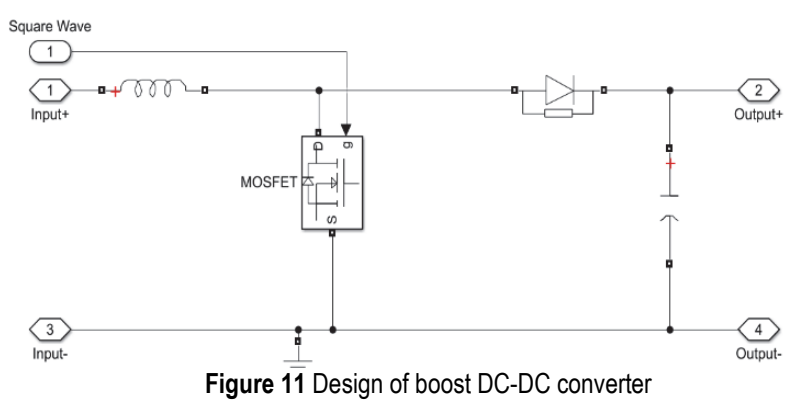

Inductance and capacitor values are determined with Eq. (30) to Eq. $(36)[18,19]$.

$D_{\min }=\frac{V_{0}-V_{s_{\text {maks }}}}{V_{0}}$

$D_{\text {maks }}=\frac{V_{0}-V_{s_{\min }}}{V_{0}}$

$\Delta I_{L}=\Delta i_{L} \cdot \frac{V_{0} \cdot I_{0}}{V_{s_{\min }}}$

$L_{\text {min }}=\frac{V_{s_{\min }} \cdot D_{\text {maks }}}{\Delta I_{L} \cdot f}$

$\Delta I_{L}=\Delta i_{L} \cdot \frac{V_{0} \cdot I_{0}}{V_{s_{\text {maks }}}}$

$L_{\text {min }}=\frac{V_{s_{\text {maks }}} \cdot D_{\text {min }}}{\Delta I_{L} \cdot f}$

$C=\frac{D_{\text {maks }}}{R \cdot \frac{\Delta V_{0}}{V_{0}} \cdot f}$

The boost converter circuit designed in the second part of the study must have a fixed output voltage of $5 \mathrm{~V}$ for the smartphone battery charge. For this reason, it has been designed using constant voltage charging method. At the same time, the second output of the design gives $8.4 \mathrm{~V}$ as output voltage. This output is designed in accordance with the system, which is most preferred by professional bikers for night driving, with LED lamps, which gives 1100 
lumen as a luminous flux and has a Li-ion rechargeable battery.

These two outputs for smart phone and bicycle lighting charging cannot be used at the same time. Considering the battery capacities and charging times, it was decided that both outputs should switch on separately. The MATLAB/Simulink model of the boost converter charging circuit, which provides energy transfer from the storage battery to the smart phone and bicycle headlight battery, is shown in Fig. 12.

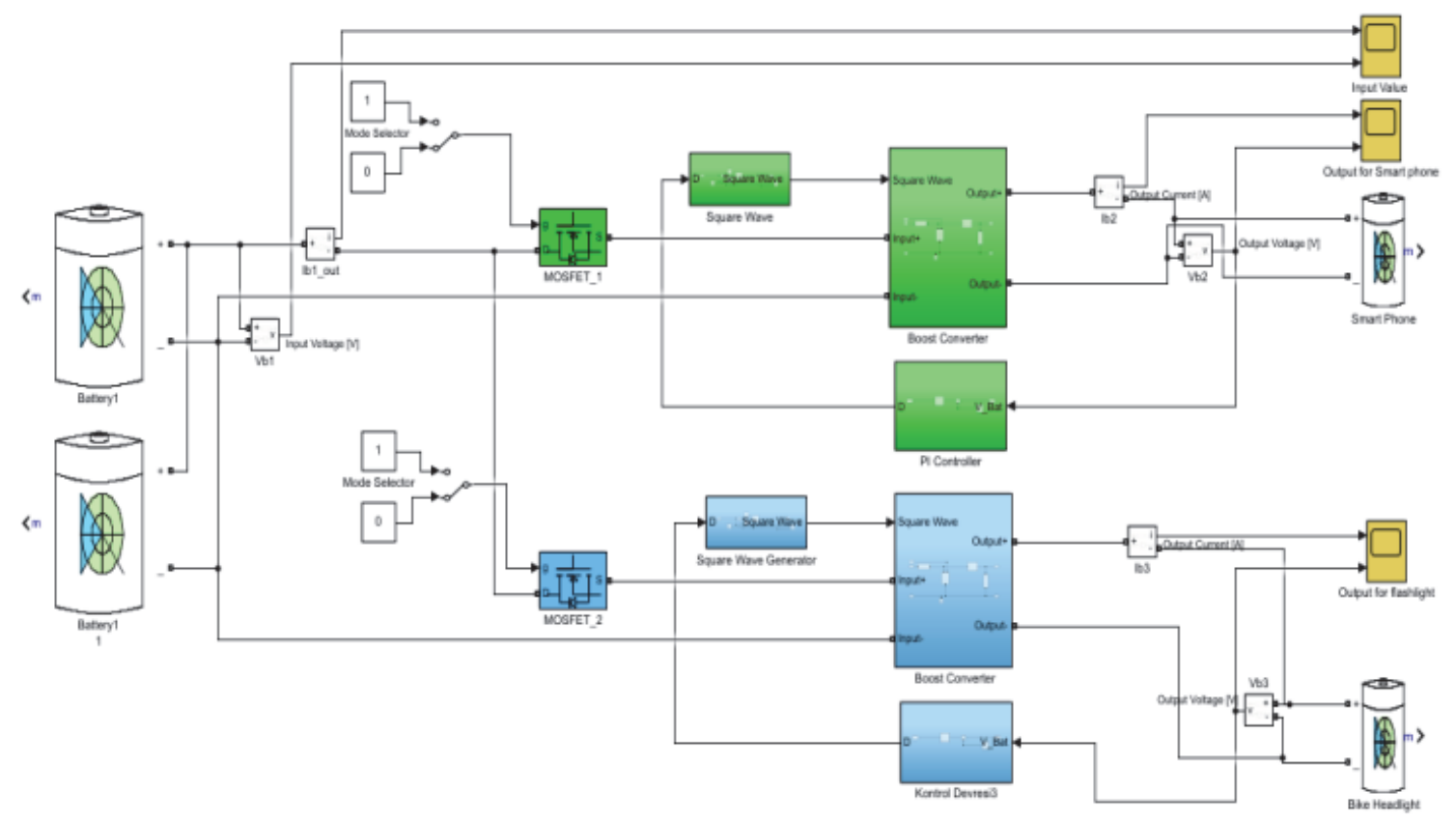

Figure 12 MATLAB/Simulink model of boost converter

\section{SIMULATION RESULTS}

In order to have a realistic approach in MATLAB/Simulink modelling used for charging the storage battery from the dynamo, the dynamo voltages are taken as $5 \mathrm{~V}, 7 \mathrm{~V}$ and $12 \mathrm{~V}$. These voltage values were taken from the dynamo by road test. In the road test, low climbing speed, moderate speed cruising on straight road and high-speed downhill were considered. Therefore, these 3 different voltage conditions were analysed in the simulation study.
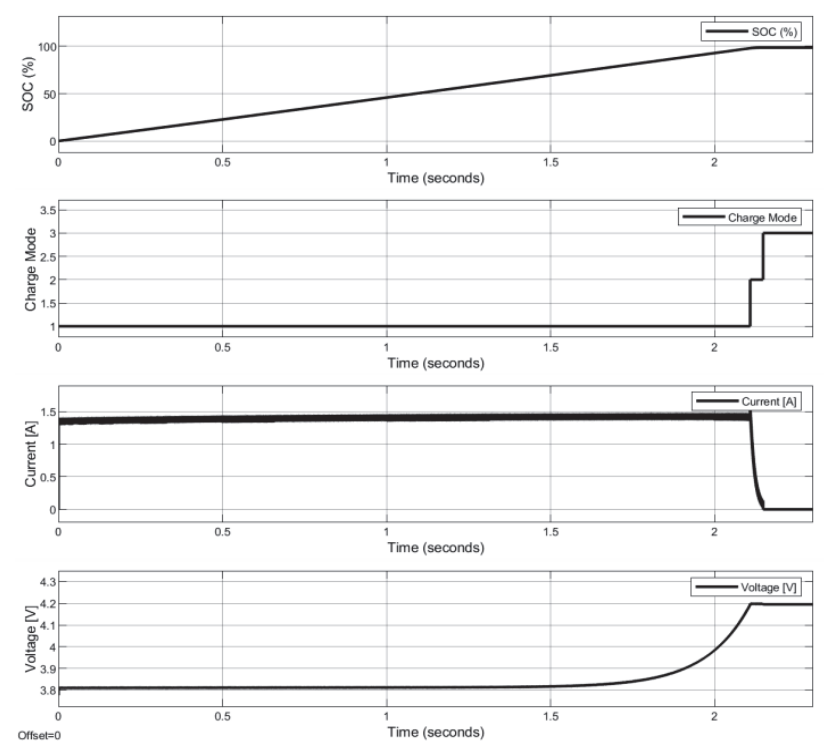

Figure 13 Results of buck DC / DC converter charge circuit for $12 \mathrm{~V}$
State of charge (SoC), charging mode, voltage and current graphs of the buck DC/DC converter MATLAB/Simulink charging circuit are given in Fig. 13. In the charge mode graph, constant current, constant voltage and charging stop states are expressed by charge mode 1 , charge mode 2 and charge mode 3 , respectively. Since the capacity of the storage battery used in this study is $8000 \mathrm{mAh}$, it takes quite a long time to model the full charging process. Therefore, during the modelling phase, the battery capacities were reduced. In the simulation, the battery capacity value was determined as $0.8 \mathrm{mAh}$.

As seen in Fig. 13, while the voltage of the storage battery is less than $4.2 \mathrm{~V}$, the battery is charged with 1.29 $\mathrm{A}$ as a constant current. When the voltage of battery reaches $4.2 \mathrm{~V}$, the charging current decreases. When the charge current reaches the previously determined $0.03 \mathrm{~A}$, the battery charge stops. The storage batteries fully charge time is approximately 2.5 seconds, for the case where the battery capacity is $0.8 \mathrm{mAh}$ and the dynamo output voltage is $12 \mathrm{~V}$. Storage battery charging time is 6.5 seconds for 7 $\mathrm{V}$ dynamo output voltage and 12.5 seconds for $5 \mathrm{~V}$. Accordingly, the charging time of storage batteries is approximately 7 hours with $12 \mathrm{~V}$ source voltage, 18 hours for $7 \mathrm{~V}$ source voltage and 35 hours for $5 \mathrm{~V}$ source voltage.

The capacity value of the smart phone and bicycle headlight battery charged from the storage battery is taken as $1600 \mathrm{mAh}$. Accordingly, the output values of the boost converter circuit used for the smartphone battery are shown in Fig. 14.

Fig. 14a shows that the drawn current from the storage battery is within the specified current limits and the battery voltage is approximately the same as the nominal voltage value of the battery. It is seen in Fig. $14 \mathrm{~b}$ that the targeted output values of $5 \mathrm{~V}, 2 \mathrm{~A}$ have been reached at the output 
of the boost DC / DC converter circuit. In addition, it is understood from the output voltage-time graph that the output voltage ripple value is lower than $1 \%$. This value is the targeted output voltage ripple value.

The circuit input and output values of the storage battery connected to the bicycle headlight battery are given in Fig. 15. Fig. 15a exhibits that the input current is within specified current limits and the battery voltage is equal to the rated voltage value. It can be seen in Fig. $15 \mathrm{~b}$ that the targeted output sizes of $8.4 \mathrm{~V}-1.8 \mathrm{~A}$ have been reached. It is also seen the output voltage ripple value is less than $1 \%$.
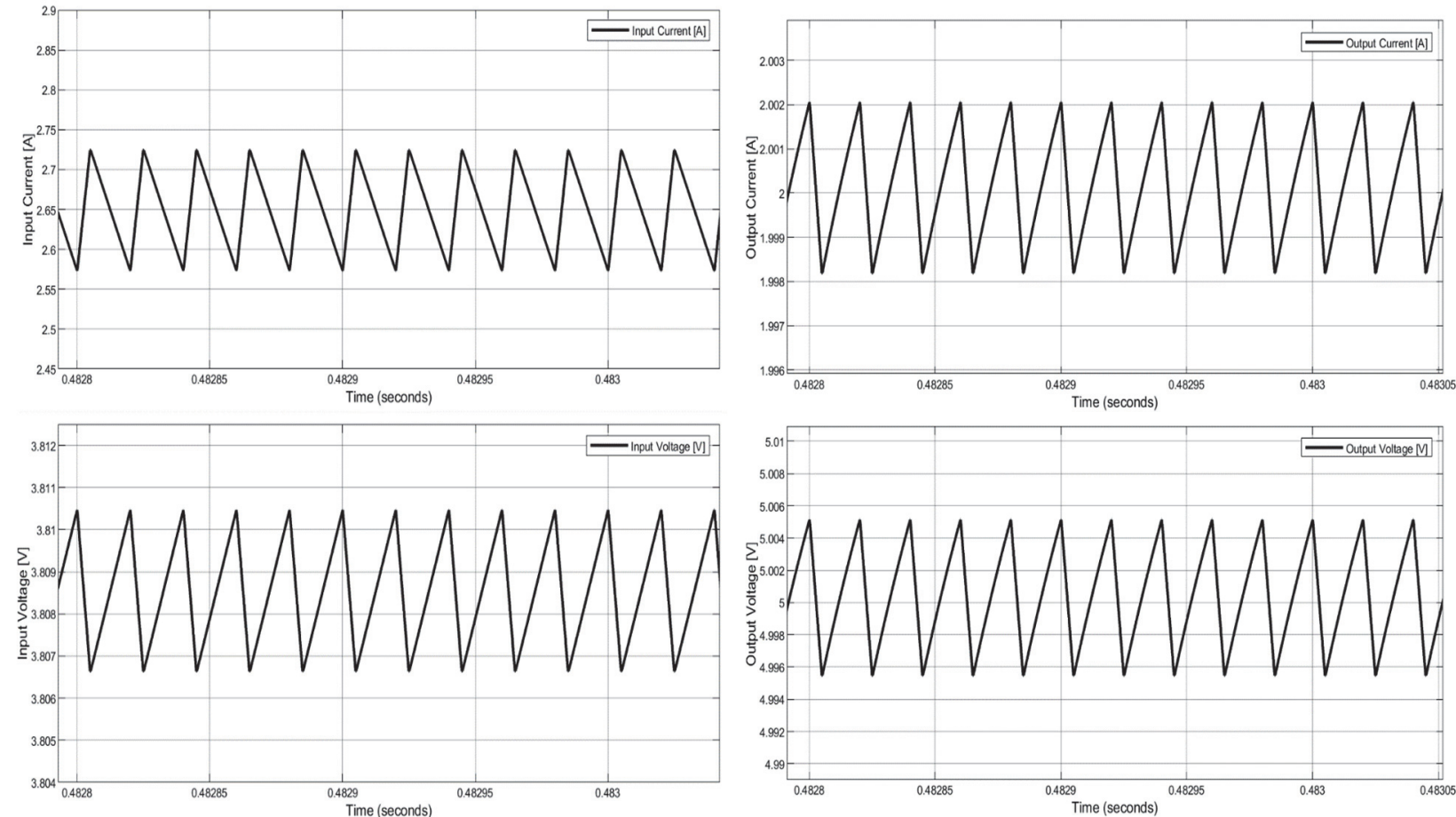

(a)

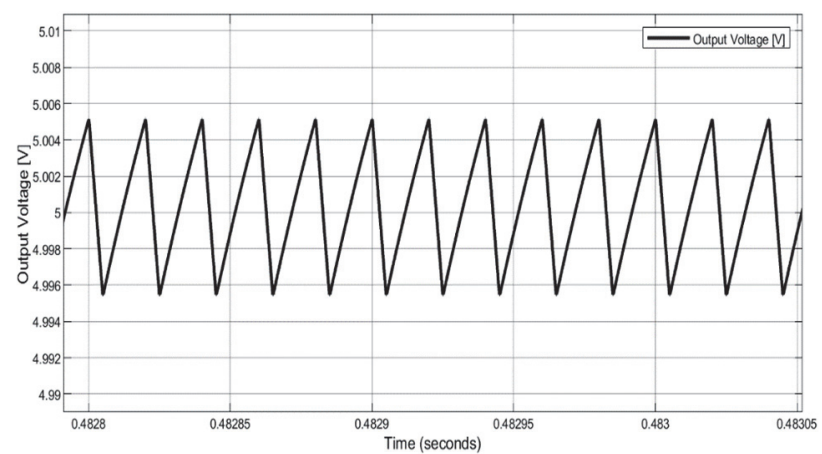

(b)

Figure 14 (a) input and (b) output results of boost DC/DC converter for smart phone battery
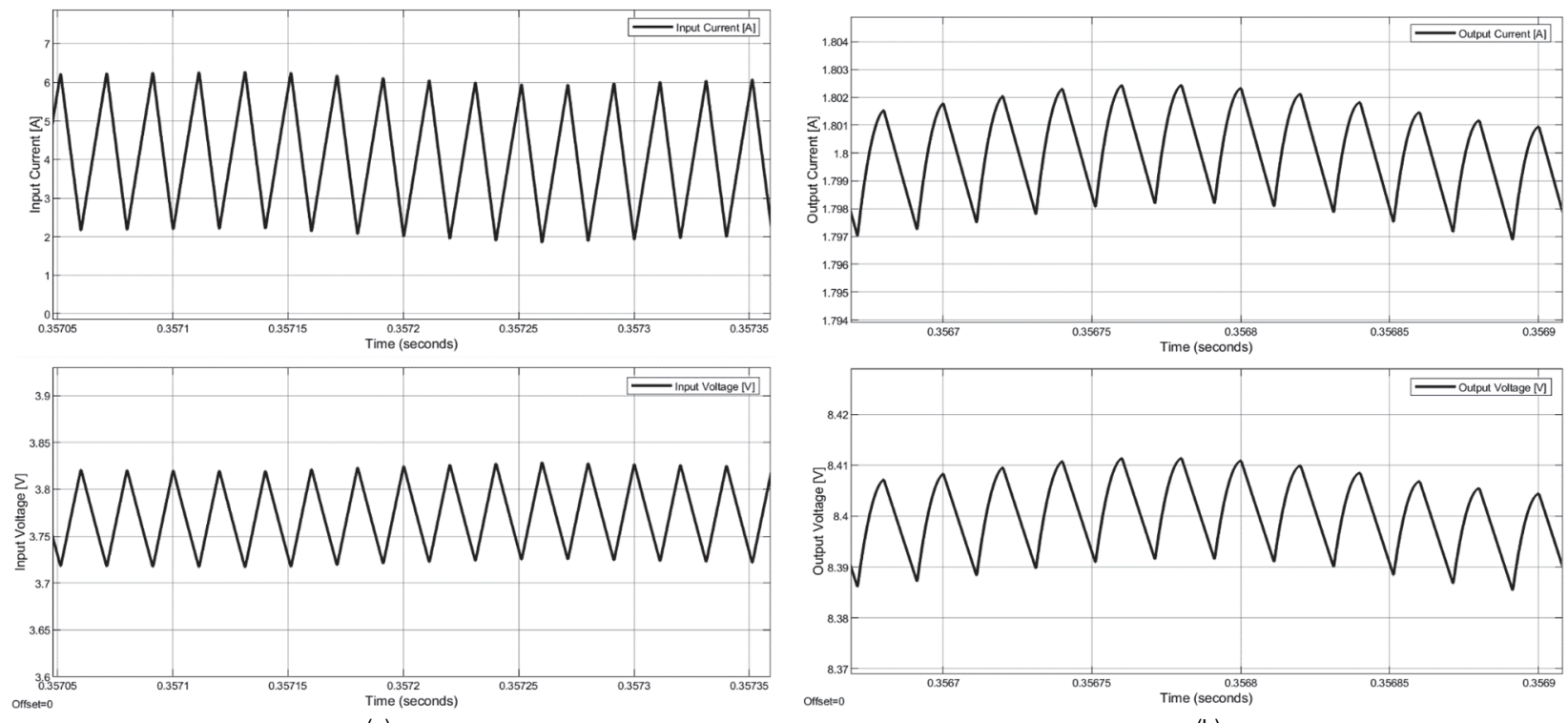

(a)

(b)

Figure 15 (a) input and (b) output results of boost DC / DC converter for bicycle headlight battery

\section{EXPERIMENTAL RESULTS}

After the simulation results were seen to be suitable, a printed circuit board (PCB) was manufactured that provides battery charging with multiple output for bikers. The circuit board shown in Fig. 16 has been connected with the battery and dynamo. Bike trainer was used for the realization of the road test conditions.
Low, medium and high-speed behaviours were determined as driving conditions in the road test. It was observed that low speed dynamo generates $5 \mathrm{~V}$, medium speed $7 \mathrm{~V}$ and high speed $12 \mathrm{~V}$ voltage. In the road test, 30 minutes trials were made for low, medium and high-speed driving. In high speed driving, it is seen that the battery charge current value is around 1.2 A and the voltage charge is $3.8 \mathrm{~V}$. In medium speed driving, it is seen that the battery charge current value is around $0.45 \mathrm{~A}$ and the voltage 
charge is $3.8 \mathrm{~V}$. In low speed driving, it is seen that the battery charge current value is around $0.2 \mathrm{~A}$ and the voltage charge is $3.8 \mathrm{~V}$. In order to reflect the reality in the continuation of the road test, the ride was carried out with spontaneous speed changes.

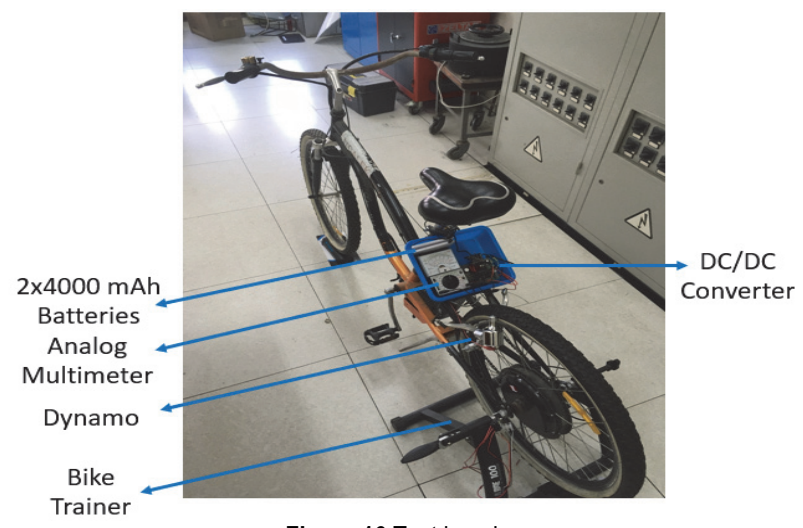

Figure 16 Test bench

As a result of this road test, which varies, two 4000 mAh batteries can be charged in approximately 22 hours. Although the charging time seems very long, $2000 \mathrm{mAh}$ is enough for a standard smartphone. Therefore, bikers can use storage batteries without being fully charged. The circuit obtained from this study will be useful especially for bikers who drive long distances and rural bikers.

When the storage battery, which is charged from the dynamo, is connected to the smartphone as shown in Fig. 17 , it has been seen the smartphone can be fully charged in approximately 1.2 hours. When the same connection was connected to the bicycle headlight, it was found that it could be charged in about 1 hour.

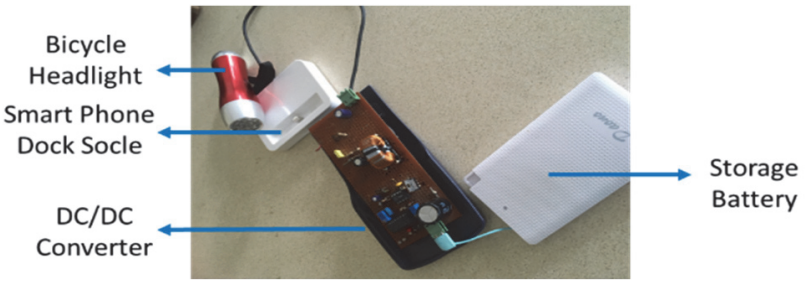

Figure 17 Smart phone Charging with the proposed system

Output values of buck and boost converter are shown in Fig. 18. The numerical results of the simulations and experiments are as shown in Tab. 4.
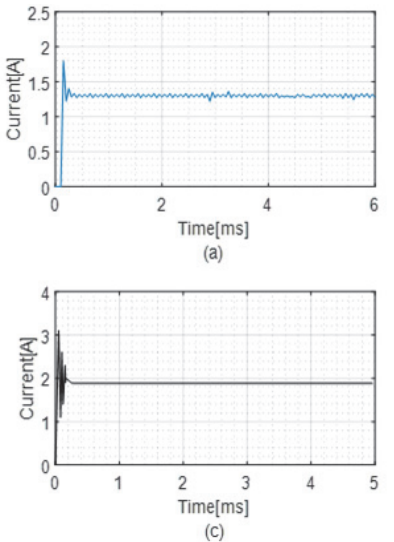

Figure 18 (a) Output current of buck converter (b) Output voltage of buck converter (d) Output current of boost converter (e) Output voltage of boost
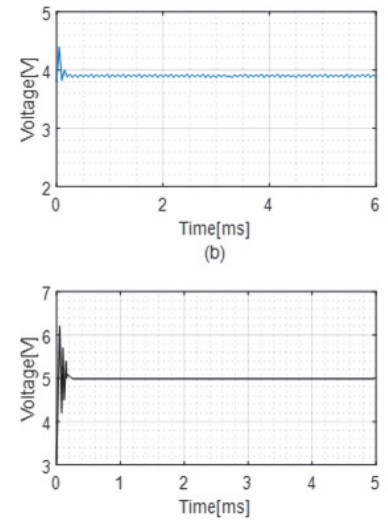

(d) converter
Table 4 Numerical results of the simulation and experiments

\begin{tabular}{|c|c|c|c|c|c|c|}
\hline & \multicolumn{3}{|c|}{ Simulation } & \multicolumn{3}{c|}{ Experiment } \\
\hline $\begin{array}{c}\text { Converter } \\
\text { Type }\end{array}$ & $\begin{array}{c}\text { Output } \\
\text { Voltage } \\
\text { / V }\end{array}$ & $\begin{array}{c}\text { Output } \\
\text { Current } \\
\text { / A }\end{array}$ & $\begin{array}{c}\text { Duty } \\
\text { Ratio }\end{array}$ & $\begin{array}{c}\text { Output } \\
\text { Voltage } \\
/ \mathrm{V}\end{array}$ & $\begin{array}{c}\text { Output } \\
\text { Current } \\
/ \mathrm{A}\end{array}$ & $\begin{array}{c}\text { Duty } \\
\text { Ratio }\end{array}$ \\
\hline Buck & 4.2 & 1.29 & 0.35 & 3.8 & 1.28 & 0.32 \\
\hline Boost & 5 & 2 & 0.16 & 5 & 1.92 & 0.16 \\
\hline
\end{tabular}

\section{CONCLUSION}

Bicycles will be very important in the near future as an environmentally friendly and sustainable type of transportation. Bicycles are an essential part of life in many large cities. One of the biggest problems of travellers and long-distance cyclists is charging their battery-powered devices. This study provides a device that offers battery charging with riding a bike. A model has been created that can charge the batteries of smartphones and bicycle headlight, which are the most needed by bikers. The cyclists will charge these batteries with the energy obtained as a result of the movement of the bicycle. This system, made without using fossil fuels, is very important for clean environment. As a result of this study, bikers need to use the electronic circuit, which is the subject of the study, and ride for about 6 hours to charge their smartphone batteries. They need to cycle for about 3 hours to recharge the bicycle headlight. Thus, the problem of charging electronic devices will be solved for bikers. Using this system commonly, proposes a solution to decrease energy consumption. This contributes to the targets of sustainable and environment friendly cities in development plans of almost every country.

\section{REFERENCES}

[1] Chen, C. \& Lee, H. (2017). How to promote bike tourism globally. Tourism and hospitality management, 23(1), 1-16. https://doi.org/10.20867/thm.23.1.2

[2] Wu, J., Yang, M., Sun, S., \& Zhao, J. (2018). Modeling travel mode choices in connection to metro stations by mixed logit models: a case study in Nanjing, China. Promet-Traffic \& Transportation, 30(5), 549-61. https://doi.org/10.7307/ptt.v30i5.2623

[3] Mei, Z., Wang, D., Chen, J., \& Wang, W. (2014). Investigation of bicycle travel time estimation using bluetooth sensors for low sampling rates. Promet-Traffic \& Transportation, 26(5), 383-91. https://doi.org/10.7307/ptt.v26i5.1343

[4] Wang, H., Si, H., \& Wang, X. (2019). Cyclist's intention identification on pedestrian-bicycle mixed sections based on phase-field coupling theory. Promet-Traffic \& Transportation, 31(3), 233-44. https://doi.org/10.7307/ptt.v31i3.2927

[5] Gehrke, S. R, Akhavan, A., Furth, P. G, Wang, Q., \& Reardon, T. G. (2020). A Cycling-focused accessibility tool to support regional bike network connectivity. Transportation Research Part D: Transport and Environment, 85, 102388. https://doi.org/10.1016/..trd.2020.102388

[6] Chevalier, A., Charlemagne, M., \& Xu, L. (2019). Bicycle acceptance on campus: influence of the built environment and shared bikes. Transportation Research Part D: Transport and Environment, 76, 211-235. https://doi.org/10.1016/j.trd.2019.09.011

[7] Sohrabi, S. \& Ermagun, A. (2021). Dynamic bike sharing traffic prediction using spatiotemporal pattern detection. 
Transportation Research PartD: Transport and Environment, 90, 102647. https://doi.org/10.1016/j.trd.2020.102647

[8] Viswanatha, V. \& Venkata Siva Reddy, R. (2018). Microcontroller based bidirectional buck-boost converter for photo-voltaic power plant. Journal of Elec. Systems and Info. Tech., 5(3), 745-758. https://doi.org/10.1016/j.jesit.2017.04.002

[9] Hassoune, A., Khafallah, M., Mesbahi, A., \& Bouragba, T. (2018). An Improved Approach of Control for a Battery Charger Based Forward Converter and SEPIC.6th International Renewable and Sustainable Energy Conference, Rabat, Morocco, 1-6. https://doi.org/10.1109/IRSEC.2018.8703032

[10] Tran, V. L., Tran, N. T., Yu, S. H., Park, Y., \& Choi, W. (2015). Design of a nonisolated fuel cell boost charger for lithium polymer batteries with a low output ripple. IEEE Transactions on Energy Conversion, 30(2), 605-614. https://doi.org/10.1109/TEC.2014.2363088

[11] C, P. K., K. S., \& N., R. J. (2020). Soft switching hybrid resonant boost converter for energy harvesting Application. 3rd International Conference on Intelligent Sustainable Systems (ICISS), Tamilnadu, India, 1416-1422. https://doi.org/ 10.1109/ICISS49785.2020.9315922

[12] Pandey, R. \& Singh, B. (2021). A Cuk converter and resonant LLC converterbased e-bike charger for wide output voltage variations. IEEE Trans. on Industry Applications, 110. https://doi.org/10.1109/TIA.2021.3066089

[13] Tsai, C., Lin, W., Lin, C., \& Wu, M. (2010). Designing a fast battery charger for electric bikes. 2010 Int. Conference on System Science and Engineering, Taipei, Taiwan, 385-389. https://doi.org/10.1109/ICSSE.2010.5551713

[14] Cheng, Z., Wang, L., Liu, J., \& Lv, J. (2016). Estimation of state of charge of lithium-ion battery based on photovoltaic generation energy storage system. Tehnički vjesnik, 23(3), 695-700. https://doi.org/10.17559/TV-20150314130830

[15] Uddin, M. R, Tasneem, Z., Annie, S. I., \& Salim, K. M. (2017). A high capacity synchronous buck converter for highly efficient and lightweight charger of electric easy bikes. 2017 Int. Conf. on Electrical, Comp. and Communication Engineering (ECCE), Cox's Bazar, 392-395. https://doi.org/10.1109/ECACE.2017.7912936

[16] Kulkarni, S., Walavalkar, N., Chhatre, V., Singh, P., \& Sharma, P. (2020). Review of optimization of charge on VRLA battery and lithium ion battery operated bike. 2020 International Conference on Convergence to Digital World Quo Vadis (ICCDW), Mumbai, India. 2020, 1-5. https://doi.org/10.1109/ICCDW45521.2020.9318678

[17] Zhang, L., Dong, W., Yang, Y., \& Sun, M. (2019). Modeling and simulation of working characteristics of lithium titanate batteries for emergency power transmission. Tehnički vjesnik, 26(1), 263-269. https://doi.org/10.17559/TV-20180829092302

[18] Hart, D. W. (2011). Power Electronics. New York, USA:McGraw-Hill Companies.

[19] Mohan, N., Undeland, T. M., \& Robbins, W. P. (2002). Power Electronics; Converters, Applications, and Design. New York, USA:John Wiley \& Sons, Inc.

[20] Farooq, A., He, C., \& Chen, G. (2018). A Three phase interleaved boost converter with $\mathrm{L} \& \mathrm{C}$ voltage extension mechanism. Tehnički vjesnik, 25(1), 52-59. https://doi.org/10.17559/TV-20150816123731

[21] Marimuthu, M. \& Vijayalakshmi, S. (2020). Symmetric multi-level boost inverter with single DC source using reduced number of switches. Tehnički vjesnik, 27(5), 15851591. https://doi.org/10.17559/TV-20190717065800

[22] Šunde, V., Jakopović, Ž., Benčić, Z., \& Pelin, D. (2021). Common characteristics of power conversion circuits topology, function and power semiconductor switches. Tehnički vjesnik, 28(1), 313-320.
https://doi.org/10.17559/TV-20191126172929

[23] Marin-Garcia, G., Vazquez-Guzman, G., Sosa, J. M., Lopez, A. R., Martinez-Rodriguez, P. R., \& Langarica, D. (2020). Battery types and electrical models: A Review. 2020 IEEE International Autumn Meeting on Power, Electronics and Computing (ROPEC), Ixtapa, Mexico, 1-6. https://doi.org/10.1109/ROPEC50909.2020.9258711

[24] Buchmann, I. (1999). Understanding your batteries in a portable world. Article on battery choice and how to maximize service life. Fourteenth Annual Battery Conference on Applications and Advances. Proceedings of the Conference (Cat. No.99TH8371), Long Beach, CA, USA, 369-373. https://doi.org/10.1109/BCAA.1999.796021

[25] Pandžić, H. \& Bobanac, V. (2019). An accurate charging model of battery energy storage. IEEE Transactions on Power Systems, 34(2), 1416-1426. https://doi.org/10.1109/TPWRS.2018.2876466

[26] Kivrak, S., Özer, T., \& Oğuz, Y. (2018). Battery management system implementation with passive control method. IV Int. Conference on Information Technologies in Engineering Education (Inforino), Moscow, Russia, 1-4. https://doi.org/10.1109/INFORINO.2018.8581758

[27] Mukherjee, N. \& De, D. A. (2017). New state-of-charge control derivation method for hybrid battery type integration. IEEE Transactions on Energy Conversion, 32(3), 866-875. https://doi.org/10.1109/TEC.2017.2695242

\section{Contact information:}

\section{Ali Sinan CABUK, Lecturer, PhD}

Istanbul Technical University,

Electrical \& Electronics Eng. Faculty, Electrical Engineering Dept.,

Istanbul Technical University,

ITÜ Ayazağa Campus 34469, Istanbul, Turkey

E-mail: ascabuk@itu.edu.tr 